\title{
Evaluation of the Impact of Psychoactive Substances on Adolescents' Self-Esteem Attending School in Kenitra, Morocco
}

\author{
Ibtissam Cherkaoui El Malki', Imad Echerbaoui', Khaoula Mammad', Youssef El Madhi², \\ Ahmed Omar Touhami Ahami ${ }^{1}$ \\ ${ }^{1}$ Unit of Cognitive Behavioral Neurosciences \& Nutritional Health, Department of Biology, Faculty of Sciences, Ibn Tofail \\ University, Kenitra, Morocco \\ ${ }^{2}$ Regional Center of Trades of Education and Training, Rabat, Morocco \\ Email: cherkaouibis@gmail.com
}

How to cite this paper: El Malki, I. C., Echerbaoui, I., Mammad, K., El Madhi, Y., \& Ahami, A. O. T. (2018). Evaluation of the Impact of Psychoactive Substances on Adolescents' Self-Esteem Attending School in Kenitra, Morocco. Psychology, 9, 705-713. https://doi.org/10.4236/psych.2018.94044

Received: March 25, 2018

Accepted: April 17, 2018

Published: April 20, 2018

Copyright $\odot 2018$ by authors and Scientific Research Publishing Inc. This work is licensed under the Creative Commons Attribution International License (CC BY 4.0).

http://creativecommons.org/licenses/by/4.0/

\begin{abstract}
Adolescence is a transitional stage from childhood to adulthood, marked by cerebral maturation accompanied by a neurodevelopmental upheaval. It is a critical biological stage of high vulnerability for the consumption of psychoactive substances (PAS), but also a phase of identity research influenced by the level of self-esteem. The objective of this study is to explore the prevalence of consumption of the PAS and the links with the levels of self-esteem among adolescents attending school in Kenitra. Moreover, the study is transversal, including 714 young students (high school students) aged 15 to 21 years. The instrument used is an anonymous self-questionnaire centered on the uses, attitudes and opinions relating to psychoactive substances, self-questionnaire for adolescents: Rosenberg's Self-esteem Scale. Our result shows also a deficit of self-esteem in both adolescent populations. However, it is more expressed among consumers $(\mathrm{t}=$ $-7.191, p<0.001)$. Thus, $57.99 \%$ of consumers have low self-esteem and $26.04 \%$ have very low self-esteem. While among the non-consumer population, 50.28\% have low self-esteem and $9.72 \%$ have very low self-esteem.
\end{abstract}

\section{Keywords}

Psychoactive Substances, Self-Esteem, Adolescents, Impact, Evaluation, Morocco

\section{Introduction}

Adolescence is a critical biological step of greater vulnerability for substance abuse experiments and the acquisition of addictive disorders. Indeed, there are neurodevelopmental features in adolescence: a greater activity of the dopa- 
minergic system and an immaturity of serotonergic inhibitory system, which promote impulsivity and seek new sensations (Andrew et al., 2003). Otherwise, adolescence is considered a risk period for the consumption of psychoactive substances (Beck \& Legleye, 2009). Of these, we have tobacco, alcohol and cannabis that are the substances most commonly consumed by adolescents (Bauman \& Phongsavan, 1999; Johnston et al., 2010; Smart \& Ogborne, 2000; Spilka et al., 2012). The latest Mediterranean School Survey Project on Alcohol and Other Drugs (MEDSPA) report (2014) (Toufiq et al., 2014) indicates that the prevalence of the use of different psychoactive substances among Moroccan adolescents aged 15 to 17 is as follows: Tobacco 17\%, Alcohol 9\%, Haschich 9\%.

On the other hand, adolescence induces important changes in the level of identity that are not without affecting the self-esteem. Therefore, a significant drop in her level observed in early adolescence, more marked for girls than for boys (Benjet \& Hernandez-Guzman, 2001; Robins et al., 2002). This low self-esteem may be associated with many psychiatric disorders in adolescents (Oliveira et al., 2016) or abuse and dependence on psychoactive substances (Akerlind et al., 1988; Backer-Fulghum et al., 2012).

\section{Materials \& Methods}

\subsection{Participants}

The sample consists of 714 (430 boys and 284 girls) subjects from a population of adolescents from high schools of different specialities. Mean age was 17.39 years $(\mathrm{SD}=1.47),(15-21$ years $)$.

\subsection{Measuring Instruments}

\subsubsection{Auto-Questionnaire}

It allowed recording the socio-demographic information of the student, the knowledge and the taking of the different PAS (tobacco, alcohol, cannabis).

Auto-questionnaire:

The instrument used is an anonymous self-questionnaire focused on the uses and attitudes relating to psychoactive substances. It was inspired by the model of the school survey on alcohol, tobacco and other drugs in the Mediterranean region (MedSPAD).

The questions are about the information:

- Sociodemographic of the student (age, sex, socioeconomic level ...), about parents and friends (school level of parents, friends, and habits of taking drugs ...);

- Schooling (notes during the last semester, absenteeism, fugues ...);

- The taking of psychoactive substances (tobacco, alcohol, cannabis ...);

- The sources and facilities of power of attorney for drugs.

\subsubsection{Rosenberg Self-Esteem Scale}

It measures the level of self-esteem; composed of ten items. Five items are presented in positive form (items 1, 2, 4, 6 and 7) and five items in negative form 
(items $3,5,8,9$ and 10), in order to limit the effect of social desirability. Responses generally rated on a four-point Likert scale from strongly disagree to strongly agree (depending on your agreement with the statement: strongly agree, agree, disagree, or strongly disagree). The rating of negative items reversed; the result is a mark of self-esteem (Rosenberg, 1965).

\subsection{Procedure}

This study took place in high schools in the Kenitra city of Morocco. We collected the data in the form of group handouts in a classroom of the institution, in the presence of the investigator with the objective explanation of the study. Both tests translated into Arabic and explained in simple terms. To avoid any bias, a period outside exams, parties and school holidays was chosen. The survey began on May 13, 2016 and lasted 6 days.

\subsection{Statistical Analysis}

The processing and statistical analysis of the data done with the software: SPSS software V.20 and Microsoft Office Excel 2016. The statistical tests used are $\chi^{2}$ test and Student's t test. The tests are considered significant for a degree of significance $p<0.05$.

\section{Results}

\subsection{Regular Consumption of Psychoactive Substances in Schools}

The table below shows that regular smoking is $16.38 \%$. (14.52\% are girls and $85.47 \%$ are boys); cannabis is $6.72 \%$. (1.7\% are girls and $95.83 \%$ are boys); and alcohol is $5.88 \%$. (2.56\% are girls and $92.86 \%$ are boys). Moreover, the prevalence of tobacco, cannabis and alcohol use is significantly different between girls and boys (Table 1).

\subsection{Rosenberg Self-Esteem scale (RSE)}

\subsubsection{Prevalence of Overall Self-Esteem Scale by Gender}

In the general population, there are fluctuations in the level of self-esteem in the adolescent's course. Thus, at the beginning of mid-teens, both sexes show lower self-esteem for girls than for boys, these levels of self-esteem will then rise until they reach a maximum by the end of mid-teens and the beginning of late adolescence; then a fall is observed until the end of adolescence. Girls have low self-esteem relative to boys $(t=2.159, p<0.031)$ (see Figure 1 ).

\subsection{Consumption of PAS and Self-Esteem among High School Students}

The following Table 2 indicates that a self-esteem deficit more expressed among consumers $(t=-7.191, p<0.001): 57.99 \%$ of consumers have low self-esteem and $26.04 \%$ have very low self-esteem. While among the non-consumer population, $50.28 \%$ have a low ES and $9.72 \%$ have very low SE. 
Table 1. Prevalence of regular consumption of psychoactive substances in both sexes in school.

\begin{tabular}{cccccc}
\hline & \multicolumn{5}{c}{ Regular use of psychoactive substances in both sexes } \\
\cline { 2 - 6 } $\begin{array}{c}\text { Psychoactives } \\
\text { substances }\end{array}$ & $\mathrm{n}=284(39.8 \%)$ & \multicolumn{3}{c}{$\begin{array}{c}\text { BOYS } \\
\mathrm{n}=430(60.2 \%)\end{array}$} \\
\cline { 2 - 6 } & $\mathrm{n}$ & 14.52 & 100 & 85.47 & $\chi^{2}$ \\
\hline Tobacco & 17 & 1.7 & 46 & 95.83 & $27.231^{* *}$ \\
Cannabis & 2 & 2.56 & 39 & 92.86 & $19.838^{* *}$ \\
Alcohol & 3 & 714 & & & \\
Total & & & & & \\
\hline
\end{tabular}

${ }^{* *} p<0.000$.

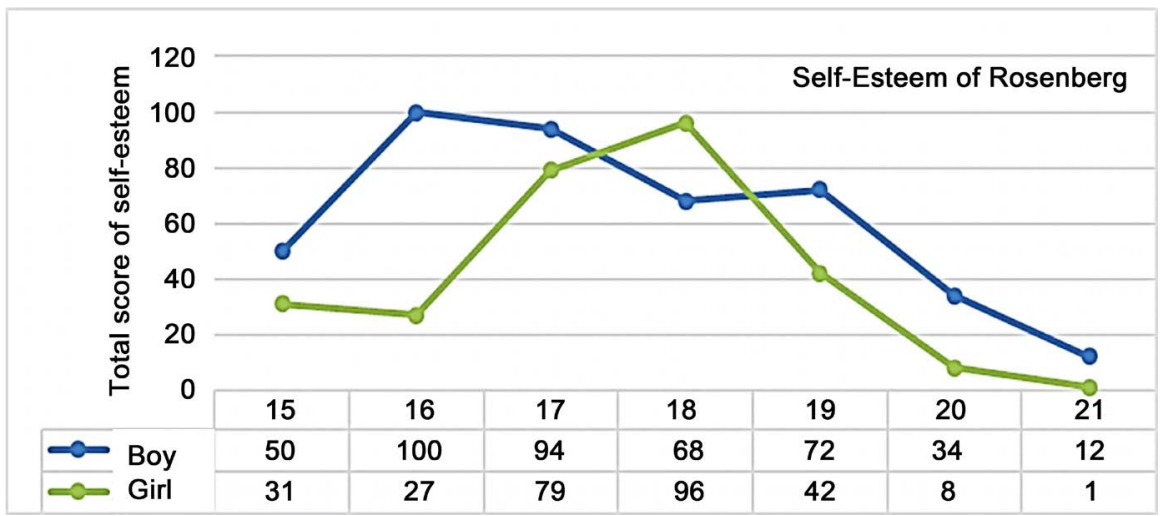

Figure 1. Prevalence of Rosenberg's self-esteem scale by sex.

Table 2. Consumption of PAS and self-esteem among students.

\begin{tabular}{cccccc}
\hline & \multicolumn{2}{c}{ Non-consumer } & \multicolumn{3}{c}{ Regular consumer } \\
\cline { 2 - 6 } Estime de soi & $\mathrm{n}=545(76.33 \%)$ & \multicolumn{2}{c}{$\mathrm{n}=169(23.66 \%)$} & $\mathrm{t}$ \\
\cline { 2 - 6 } & $\mathrm{n}$ & $\%$ & $\mathrm{n}$ & $\%$ & \\
\hline Very low & 53 & 9.72 & 44 & 26.04 & -7.191 \\
Low & 274 & 50.28 & 98 & 57.99 & \\
Average & 119 & 21.83 & 23 & 13.61 & \\
Strong & 99 & 18.17 & 5 & 2.96 & \\
\hline
\end{tabular}

${ }^{*} p<0.001$.

\section{Discussion}

Studies of the prevalence of psychoactive substance use clearly show that not all different psychoactive substances are consumed in the same way or at the same age. This is all the more important to take into account that the trajectory of changes in consumption depends on the type of psychoactive substance used (Becker et al., 2012; Flory, Lynam, Milich, Leukefeld, \& Clayton, 2004; Martino, Ellickson, \& McCaffrey, 2008). In this regard, the prevalence of psychoactive substance use reported in the National Program for Assessing Student Achievement (NPASA, 2016) report is $15 \%$. In this study it is $16.38 \%$. It joins those re- 
ported by studies conducted in schools (high schools and colleges: $6.5 \%$ to $15.4 \%$ successively) (Al Idrissi 1995; Achbouk 2002; Bensalah 2010; Kaoutar et al., 2012). However, this prevalence is still lower than those reported by international studies, which are 30\% (Legleyel, Spilka, \& Le Nezet, 2007), 32.4\% Health and Consumption Investigation during Defense Preparation Call (HCIDDPC) surveys, Spilka et al., 2012) and 34\% (Chéron-Launay et al., 2011).

In addition, $6.72 \%$ of the students reported having used cannabis and 5.88\% of the alcohol regularly during the last 30 days, these results were close to the one reported in Mediterranean School Survey Project on Alcohol and Other Drugs (MEDSPAD, 2014) survey (Toufiq et al., 2014) (cannabis: 4, 7\%, alcohol: $3 \%)$. However, the 2016 NPASA report shows larger percentages estimated at $13 \%$ of students use drugs within the facility and $10 \%$ consume alcohol. Also, the HCIDDPC) survey (2014) (Spilka et al., 2012), concerned 26,351 French adolescents, shows a higher regular consumption of alcohol estimated at $12.3 \%$, and comparable for that of cannabis consumption $4 \%$.

\subsection{Overall Self-Esteem in Adolescents}

In this study, self-esteem was assessed by the Rosenberg Self-Esteem Scale (RSE), which is widely used in research on overall self-esteem at different ages of life (Maintier \& Alaphilippe, 2006; Marcouyeux-Deledalle \& Fleury-Bahi, 2007). According to the results of the assessment of self-esteem among the general population of adolescents, there are fluctuations in the level of self-esteem during adolescence. These results are consistent with those of the Birkeland longitudinal study (2012) of 1083 Swedish adolescents, which confirms that the average level of self-esteem was relatively stable but increased slowly and gradually between 14 and 23 years of age (Birkeland et al., 2012).

These fluctuations in self-esteem in adolescence observed in this study are also related to the male and female gender since low self-esteem is more marked for girls than for boys and the existence of a significant difference between the self-esteem scale score for both sexes is highlighted. This finding confirms the results of several previous studies (Seidah et al., 2004; Bégarie et al., 2011; Bolognini et al., 1996; Fourchard \& Courtinat, 2013), where the authors have already observed that boys get scores overall self-esteem better than girls.

\subsection{Consumption of PAS and Self-Esteem}

The comparison of the Rosenberg scale scores among non-consumers and consumers shows that they have lower scores on overall self-esteem, which confirms the hypothesis already proposed. The link between low self-esteem and psychoactive substance use reported in several studies (Andrew \& Duncan, 1997; Jackson et al., 1997; Pederson et al., 1998; Taylor \& Del Pilar, 1992; Walitzer \& Sher, 1996; Wasson \& Anderson, 1995). Kassel, Wardle, \& Roberts' study (2007), conducted with 212 young students, showed that low self-esteem was associated with the frequency of smoking and cannabis, but not with alcohol. 
While Andrews and Duncan (1997) report that self-esteem poorly predicted cannabis use among adolescents. Moreover, a longitudinal study of 4853 Iranian students aged 14 to 18 showed that adolescents with low self-esteem more exposed to relative risk of smoking compared to those with higher self-esteem (Khosravi et al., 2016). Other studies of cannabis-dependent adolescents who are concerned with their management point out that low self-esteem is a negative predictor of treatment outcome in these subjects (Flory et al., 2004; Ramo et al., 2005).

The mechanisms of the link between low self-esteem and use of PAS are not fully known. Thus, it suggested that the increase in alcohol and drug use would favor insertion into certain social groups (Oetting et al., 1998), or help the subject to combat the negative emotions generated by rejection or depression (Leary et al., 1995). Although causal relationships still discussed, the results of three studies suggest that altered self-esteem would precede initiation of smoking (Abernathy et al., 1995; Fergusson et al., 1995; Laure \& Binsinger, 2005). Results from two studies also indicate that low self-esteem is a stronger predictor of smoking among girls (Abernathy et al., 1995; Lewis et al., 2001).

\section{Conclusion and Perspective}

At the end of this research, which focused on 714 high school students in Kenitra, Morocco, we were able to highlight the link between the consumption of PAS and low self-esteem.

The results of this work challenge all contributors in the field of health and education, to adopt a multidisciplinary approach integrating the assessment of emotional needs in self-esteem as a protective factor of youth development school. For example, the school's investment in improving the psychic and neurocognitive factors of the adolescent through the organization of extracurricular events and activities (sports, artistic, cultural...) allows the elimination of the psychological tension and the excitement, excessive energy depletion, satisfaction of psychological needs, social adaptation and self-realization.

\section{Acknowledgements}

The authors thank all those who contributed closely or by far to the realization of this work.

\section{References}

Abernathy, T. J., Massad, L., \& Romano-Dwyer, L. (1995). The Relationship between Smoking and Self-Esteem. Adolescence, 30, 899-907.

Achbouk, A. (2002). Tabagisme en milieu scolaire à Marrakech. Rabat: Thèse doctorat en médecine.

Akerlind, I., Hörnquist, J. O., \& Bjurulf, P. (1988). Prognosis in Alcoholic Rehabilitation: The Relative Significance of Social, Psychological, and Medical Factors. International Journal of the Addictions, 23, 1171-1195. https://doi.org/10.3109/10826088809056193

Al Idrissi, M. (1995). Le Tabagisme chez les lycéens au niveau de la préfecture de Rabat. 
Rabat: Thèse doctorat en médecine.

Andrew Chambers, R., Taylor, J. R., \& Potbnza, M. N. (2003). Developmental Neurocircuity of Motivation in Adolescence: A Critical Period of Addiction Vulnerability. American Journal of Psychiatry, 160, 1041-1052. https://doi.org/10.1176/appi.ajp.160.6.1041

Andrew, J. A., \& Duncan, S. C. (1997). Examining the Reciprocal Relation between Academic Motivation and Substance Use: Effects of Family Relationships, Self-Esteem, and General Deviance. Journal of Behavioral Medicine, 20, 523-554. https://doi.org/10.1023/A:1025514423975

Backer-Fulghum, L. M., Patock-Peckham, J. A., King, K. M., et al. (2012). The Stress-Response Dampening Hypothesis: How Self-Esteem and Stress Act as Mechanisms between Negative Parental Bonds and Alcohol-Related Problems in Emerging Adulthood. Addictive Behaviors, 37, 477-484. https://doi.org/10.1016/j.addbeh.2011.12.012

Bauman, A., \& Phongsavan, P. (1999). Epidemiology of Substance Use in Adolescence: Prevalence, Trends and Policy Implications. Drug and Alcohol Dependence, 55, 187-207. https://doi.org/10.1016/S0376-8716(99)00016-2

Beck, F., \& Legleye, S. (2009). Sociologie et épidémiologie des consommations de substances psychoactives de l'adolescent. Encephale, S6, 190-201.

https://doi.org/10.1016/S0013-7006(09)73470-0

Becker, S. P., Luebbe, A. M., \& Langberg, J. M. (2012). Co-Occurring Mental Health Problems and Peer Functioning among Youth with Attention-Deficit/Hyperactivity Disorder: A Review and Recommendations for Future Research. Clinical Child and Family Psychology Review, 15, 279-302. https://doi.org/10.1007/s10567-012-0122-y

Bégarie, J., Maïano, C., \& Ninot, G. (2011). Concept de soi physique et adolescents présentant une déficience intellectuelle: effets de l'âge, du sexe et de la catégorie de poids. The Canadian Journal of Psychiatry, 56.

https://doi.org/10.1177/070674371105600308

Benjet, C., \& Hernandez-Guzman, L. (2001). Gender Differences in Psychological Well-Being of Mexican Early Adolescents. Adolescence, 36, 47-64.

Bensalah, M. (2010). Connaissances, attitudes et comportement des écoliers vis-à-vis du tabagisme à la préfecture d'Oujda. Thèse de doctorat, Maroc: Université Sidi Mohamed Ben Abdellah.

Birkeland, M. S., Melkevik, O., Holsen, I., \& Wold, B. (2012). Trajectories of Global Self-Esteem Development during Adolescence. Journal of Adolescence, 351, 43-54. https://doi.org/10.1016/j.adolescence.2011.06.006

Bolognini, M., Plancherel, B., Bettschart, W., \& Halfon, O. (1996). Self-Esteem and Mental Health in Early Adolescence: Development and Gender Differences. Journal of Adolescence, 19, 233-245. https://doi.org/10.1006/jado.1996.0022

Chéron-Launay, M. et al., (2011). Repérer les comportements addictifs chez les adolescents: Enquête en milieu lycéen. Archives de Pédiatrie, 18, 737-744. https://doi.org/10.1016/j.arcped.2011.04.019

Fergusson, D. M., Lynskey, M. T., \& Horwood, L. J. (1995). The Role of Peer Affiliations, Social, Family and Individual Factors in Continuities in Cigarette Smoking between Childhood and Adolescence. Addiction, 90, 647-660. https://doi.org/10.1111/j.1360-0443.1995.tb02203.x

Flory, K., Lynam, D., Milich, R., Leukefeld, C., \& Clayton, R. (2004). Early Adolescent through Young Adult Alcohol and Marijuana Use Trajectories: Early Predictors, Young Adult Outcomes, and Predictive Utility. Development and Psychopathology, 16, 
193-213. https://doi.org/10.1017/S0954579404044475

Fourchard, F., \& Courtinat-Camps, A. (2013). L'estime de soi globale et physique à l'adolescence. Neuropsychiatrie de l'Enfance et de l'Adolescence, 61, 333-339. https://doi.org/10.1016/j.neurenf.2013.04.005

Jackson, C., Henriksen, L., Dickinson, D., \& Levine, D. W. (1997). The Early Use of Alcohol and Tobacco: Its Relation to Children's Competence and Parent's Behavior. American Journal of Public Health, 87, 359-364. https://doi.org/10.2105/AJPH.87.3.359

Johnston, L. D., O’Malley, P. M., Bachman, J. G., \& Schulenberg, J. E. (2010). Monitoring the Future: National Results on Adolescent Drug Use. Overview of Key Findings, 2006. https://www.samhsa.gov/

Kaoutar, K., Hilali, M. K., \& Loukid, M. (2012). Tabagisme et facteurs associés des adolescents de la ville de Marrakech (Maroc). Antropo, 28, 97-104. http://www.didac.ehu.es/antropo

Kassel, J. D., Wardle, M., \& Roberts, J. E. (2007). Adult Attachment Security and College Student Substance Use. Addictive Behaviors, 32, 1164-1176. https://doi.org/10.1016/j.addbeh.2006.08.005

Khosravi, A., Asghar, M., Holakouie-Naieni, K., Mahmoodi, M., Pouyan, A. A., \& Mansournia, M. A. (2016). Causal Effect of Self-Esteem on Cigarette Smoking Stages in Adolescents: Coarsened Exact Matching in a Longitudinal Study. Osong Public Health and Research Perspectives, 7, 341-345.

Laure, P., \& Binsinger, C. (2005). Adolescent Athletes and the Demand and Supply of Drugs to Improvetheir Performance. Journal of Sports Science and Medicine, 4, 272-277.

Leary, M. R., Schereindorfer, L. S., \& Haupt, A. L. (1995). The Role of Low Self-Esteem in Emotional and Behavioral Problems: Why Is Low Self-Esteem Dysfunctional? Journal of Social and Clinical Psychology, 14, 297-314.

Legleyel, S., Spilka, S., \& Le Nezet, O. (2007). Drogues à l'adolescence en 2005-Niveaux, contextes d'usage et évolutions à 17 ans en France-Résultats de la cinquième enquête nationale ESCAPAD. Observatoire Français des Drogues et Toxicomanies.

Lewis, P. C., Harrell, J. S., Bradley, C., \& Deng, S. (2001). Cigarette Use in Adolescents: the Cardiovascular Health in Children and Youth Study. Research in Nursing and Health, 24, 27-37. https://doi.org/10.1002/1098-240X(200102)24:1<27::AID-NUR1004>3.0.CO;2-0

Maintier, C., \& Alaphilippe (2006). Validation d'un questionnaire d'auto-évaluation de soi destiné aux enfants. Année psychologique, 106, 513-542.

Marcouyeux-Deledalle, A., \& Fleury-Bahi, G. (2007). Identification au collège, identification aux pairs et estime de soi: Quelles relations avec l'image de l'établissement. L'orientation scolaire et professionnelle, 36, 203-222.

Martino, S., Ellickson, P., \& McCaffrey, D. (2008). Developmental Trajectories of Substance Use from Early to Late Adolescence: A Comparison of Rural and Urban Youth (Report). Journal of Studies on Alcohol and Drugs, 69, 430-442. https://doi.org/10.15288/jsad.2008.69.430

NPASA (2016). National Program for Assessing Student Achievement. Morocco.

Oetting, E. R., Donnermeyer, J. F., \& Deffenbacher, J. L. (1998). Primary Socialization Theory. The Influence of the Community on Drug Use and Deviance. III. Substance Use and Misuse, 33, 1629-1665. https://doi.org/10.3109/10826089809058948

Oliveira, S. E., Carvalho, H., \& Esteves, F. (2016). Internalized Stigma and Quality of Life Domains among People with Mental Illness: The Mediating Role of Self-Esteem. Jour- 
nal of Mental Health, 1, 55-61.

Pederson, L. L., Koval, J. J., McGrady, G. A., \& Tyas, S. L. (1998). The Degree and Type of Relationship between Psychosocial Variables and Smoking Status for Students in Grade 8: Is There a Dose-Response Relationship. Preventive Medicine, 27, 337-347.

Ramo, D. E., Anderson, K. G., Tate, S. R., \& Brown, S. A. (2005). Characteristics of Relapse to Substance Use in Comorbid Adolescents. Addictive Behaviors, 30, 1811-1823. https://doi.org/10.1016/j.addbeh.2005.07.021

Robins, R. W., Trzesniewski, K. H., Tracy, J. L., Gosling, S. D., \& Potter, J. (2002). Global Self-Esteem across the Life Span. Psychology and Aging, 173, 423-434. https://doi.org/10.1037/0882-7974.17.3.423

Rosenberg, M. (1965) Society and the Adolescent Self-Image. Princeton, NJ: Princeton University Press.

Seidah, A., Bouffard, T., \& Vezeau, C. (2004). Perceptions de soi à l'adolescence: Différences filles-garçons. Enfance, 56, 405-420.

Smart, R. G., \& Ogborne, A. C. (2000). Drug Use and Drinking among Students in 36 Countries. Addictive Behaviors, 25, 455-460. https://doi.org/10.1016/S0306-4603(99)00013-1

Spilka, S., Le Nézet, O., Beck, F., Ehlinger, V., \& Godeau, E. (2012). Alcool, Tabac et cannabis durant les années collège (p. 80). Tendances, OFDT.

Taylor, D. N., \& Del Pilar, J. (1992). Self-Esteem, Anxiety, and Drug Use. Psychological Reports, 71, 896-898. https://doi.org/10.2466/pr0.1992.71.3.896

Toufiq, J., El Omari, F., \& Sabir, M. (2014). Drug Use. Drug Use among Moroccan Students. School Survey, MEDSPAD, Maroc.

Walitzer, K. S., \& Sher, K. J. (1996). A Prospective Study of Self-Esteem and Alcohol Use Disorders in Early Adulthood: Evidence for Gender Differences. Alcoholism, Clinical and Experimental Research, 20, 1118-1124.

https://doi.org/10.1111/j.1530-0277.1996.tb01956.x

Wasson, D., \& Anderson, M. A. (1995). Chemical Dependency and Adolescent Self-Esteem. Clinical Nursing Research, 4, 274-289. 